\title{
Correction to: The production of UL16-binding protein 1 targeted pigs using CRISPR technology
}

\author{
Joanna Zeyland ${ }^{1} \cdot$ Magdalena Hryhorowicz $^{1} \cdot$ Agnieszka Nowak-Terpiłowska $^{1} \cdot$ Jacek Jura $^{2} \cdot$ Ryszard Słomski $^{1,3}$. \\ Zdzisław Smorąg ${ }^{2} \cdot$ Barbara Gajda $^{2}$. Daniel Lipiński ${ }^{1}$
}

Published online: 13 July 2018

(c) Springer-Verlag GmbH Germany, part of Springer Nature 2018

\section{Correction to: 3 Biotech (2018) 8:70 \\ https://doi.org/10.1007/s13205-018-1107-4}

In the online published article, first and last names of all the authors in the author group have been transposed. The correct author names are given below:

Joanna Zeyland

Magdalena Hryhorowicz
Agnieszka Nowak-Terpiłowska

Jacek Jura

Ryszard Słomski

Zdzisław Smorąg

Barbara Gajda

Daniel Lipiński
The original article can be found online at https://doi.org/10.1007/ s13205-018-1107-4.

Daniel Lipiński

lipinskidaniel71@gmail.com

Joanna Zeyland

jzeyland@gmail.com

Magdalena Hryhorowicz

magdalenahryhorowicz@gmail.com

Agnieszka Nowak-Terpiłowska

nwk.agnieszka@gmail.com

Jacek Jura

jacek.jura@izoo.krakow.pl

Ryszard Słomski

slomski@up.poznan.pl
Zdzisław Smorąg

zdzislaw.smorag@izoo.krakow.pl

Barbara Gajda

barbara.gajda@izoo.krakow.pl

1 Department of Biochemistry and Biotechnology, Poznan University of Life Sciences, Dojazd 11, 60-632 Poznań, Poland

2 Department of Animal Reproduction, National Research Institute of Animal Production, Krakowska 1, 32-083 Balice, Poland

3 Institute of Human Genetics, Polish Academy of Sciences, Strzeszyńska 32, 60-479 Poznań, Poland 